\title{
Erratum to: Effects of calcium-fortified ice cream on markers of bone health
}

\author{
L. Ferrar • R. M. van der Hee • M. Berry • C. Watson • \\ S. Miret • J. Wilkinson • M. Bradburn • R. Eastell
}

Published online: 19 February 2011

(C) International Osteoporosis Foundation and National Osteoporosis Foundation 2011

\section{Erratum to: Osteoporos Int}

\section{DOI 10.1007/s00198-010-1513-x}

The affiliation of the authors M. Berry, C. Watson and J. Wilkinson was rendered incorrectly. The correct affiliation is shown here.

The online version of the original article can be found at http://dx.doi. org/10.1007/s00198-010-1513-x.

L. Ferrar $\cdot$ R. Eastell

Sheffield NIHR Bone Biomedical Research Unit,

University of Sheffield and Sheffield Teaching Hospital

Foundation Trust, Centre for Biomedical Research,

Herries Road,

Sheffield S5 7AU South Yorkshire, UK

R. M. van der Hee $\cdot$ S. Miret

Unilever R\&D Vlaardingen,

Vlaardingen, The Netherlands

M. Berry $\cdot$ C. Watson $\cdot J$. Wilkinson

Unilever R\&D Colworth,

Colworth Science Park, Sharnbrook,

Bedfordshire, UK

\section{Bradburn}

Clinical Trials Research Unit,

School of Health and Related Research, University of Sheffield,

Sheffield, UK

R. Eastell $(\bowtie)$

Centre for Biomedical Research, Northern General Hospital,

Herries Road,

Sheffield, South Yorkshire S5 7 AU, UK

e-mail: r.eastell@sheffield.ac.uk 